\title{
Characteristics of Symptom Presentation and Risk Factors in Patients with Erosive Esophagitis and Nonerosive Reflux Disease
}

\author{
Shou-Wu Lee ${ }^{a, b}$ Teng-Yu Lee ${ }^{a, b}$ Han-Chung Lien ${ }^{a, c}$ Sheng-Shun Yang ${ }^{a, c}$ \\ Hong-Zen Yeh ${ }^{a, c}$ Chi-Sen Chang ${ }^{a, b}$ \\ aDivision of Gastroenterology, Department of Internal Medicine, Taichung Veterans General Hospital, and \\ ${ }^{b}$ Department of Internal Medicine, Chung Shan Medical University, Taichung, and ${ }^{\mathrm{C}}$ Department of Internal \\ Medicine, National Yang-Ming University School of Medicine, Taipei, Taiwan, ROC
}

\section{Key Words}

Erosive esophagitis - Gastroesophageal reflux disease .

Gender - Quality of life · Nonerosive reflux disease

\begin{abstract}
Objective: The aim of this study was to investigate the effect of gender on symptom presentation and quality of life of patients with erosive esophagitis (EE) and nonerosive reflux disorder (NERD). Subjects and Methods: Medical records from patients with gastroesophageal reflux disease (GERD) between January and December 2009 were reviewed. The patients were assigned to either the EE or the NERD group. The general demographic data, the modified Chinese GERDQ scores and the Short Form (SF)-36 life quality questionnaire scores of the two groups of patients were compared. $\boldsymbol{R e}$ sults: Of the 261 patients, 87 (33.3\%), 86 (33.0\%) and 88 (33.7\%) patients were classified into the EE, the NERD and the control groups, respectively. The patients in the EE group were significantly older $(48.94 \pm 17.38$ vs. $43.34 \pm 12.67$ years), were predominately male ( 58.6 vs. $39.5 \%)$, had more frequently hiatal hernia (34.5 vs $17.4 \%$ ), had a higher body
\end{abstract}

weight $(67.57 \pm 15.13$ vs. $61.06 \pm 11.08 \mathrm{~kg})$ and a higher body mass index ( $24.09 \pm 4.61$ vs. $22.68 \pm 3.12)$ than those in the NERD group. The GERD-specific symptom scores and the general life quality scores of the EE and the NERD groups were similar, and both groups had lower life quality scores than the control group did. The female patients with NERD had a higher frequency of GERD symptoms and lower quality of life scores. Gender had no effect on symptom scores or life quality scores in the EE group. Conclusion: The GERDspecific symptom severity and general quality of life scores of the EE and the NERD patients were similar. Gender had a great influence on symptom presentation and quality of life in patients with NERD, but not in those with EE.

ㄷ) 2014 S. Karger AG, Basel

\section{Introduction}

Gastroesophageal reflux disease (GERD) is a chronic disease that tends to relapse and cause complications. According to the Montreal definition, GERD is 'a condition which develops when the reflux of stomach contents

\begin{tabular}{ll}
\hline KARGER & $\begin{array}{l}\text { ( ) 2014 S. Karger AG, Basel } \\
1011-7571 / 14 / 0235-0460 \$ 39.50 / 0 \quad \text { Karger }\end{array}$ \\
$\begin{array}{l}\text { E-Mail karger@karger.com } \\
\text { www.karger.com/mpp }\end{array}$ & $\begin{array}{l}\text { This is an Open Access article licensed under the terms of the } \\
\text { Creative Commons Attribution-NonCommercial 3.0 Un- } \\
\text { ported license (CC BY-NC) (www.karger.com/OA-license), } \\
\text { applicable to the online version of the article only. Distribu- } \\
\text { tion permitted for non-commercial purposes only. }\end{array}$
\end{tabular}

Shou-Wu Lee, MD

Division of Gastroenterology, Department of Internal Medicine

Taichung Veterans General Hospital, 1650 Taiwan Boulevard Sect. 4

Taichung 40705, Taiwan (ROC)

E-Mail ericest429@yahoo.com.tw 
causes troublesome symptoms and/or complications' [1]. The cardinal symptoms of GERD are considered to be heartburn and regurgitation. Besides, GERD is also associated with a range of other symptoms originating in the esophagus, chest and respiratory tract [2]. Based on the presence or absence of mucosal damage, GERD patients can be classified as having either erosive esophagitis (EE) or nonerosive reflux disorder (NERD) [3]. GERD has an impact on the daily lives of affected individuals, interfering with physical activity, impairing social functioning, disturbing sleep and reducing productivity at work $[4,5]$. The aim of this study was to investigate the impact of gender on the symptom presentation and quality of life among patients with EE and NERD.

\section{Subjects and Methods}

The medical records of 261 consecutive patients at our hospital diagnosed with GERD according to the Montreal definition were collected between January and December 2009. Exclusion criteria were GERD combined with other structural gastrointestinal disorders, such as peptic ulcer disease, esophageal or gastric malignancy, prior gastric surgery, use of chronic antacid medication, such as proton pump inhibitors or $\mathrm{H}_{2}$-receptor antagonists for more than 2 months prior to the study and pregnancy.

The general data of the patients, including age, gender, body weight and body mass index (BMI), symptom duration and lifestyle habits, were recorded. All patients underwent an open-access transoral upper gastrointestinal endoscopy, and the findings of each case were recorded.

The patients were assigned to two groups according to whether they did (EE group) or did not (NERD group) have esophagocardiac mucosal break detected by upper gastroinestinal endoscopy. They were assigned to three groups: 87 to the EE group, 86 to the NERD group and 88 to the control group. All patients were asked to complete two questionnaires, the modified Chinese GERD questionnaire (GERDQ) and the Short Form (SF)-36 life quality questionnaire (Chinese version). Patients without typical symptoms of GERD and normal endoscopic findings, but who might have mild symptoms of dyspepsia, during the same period of time were assigned to the control group. The general data and questionnaire scores were analyzed.

The modified Chinese GERDQ includes questions about the severity and frequency of the symptoms of regurgitation and heartburn, and the answers were graded on a three-point Likert scale as follows: mild = symptoms that can be easily ignored, moderate $=$ awareness of symptoms but easily tolerated, and advanced severity = symptoms sufficient to interfere with normal activities. Symptoms occurring at least once per month, at least once a week, and at least once a day were classified as low, middle and high frequency symptoms, respectively.

The SF-36 questionnaire measures the general quality of life and so allows comparisons between the different disease states. It measures the health status in eight domains: physical functioning, role limitations - physical, bodily pain, general health, vitality, social functioning, role limitations - emotional, and mental health.

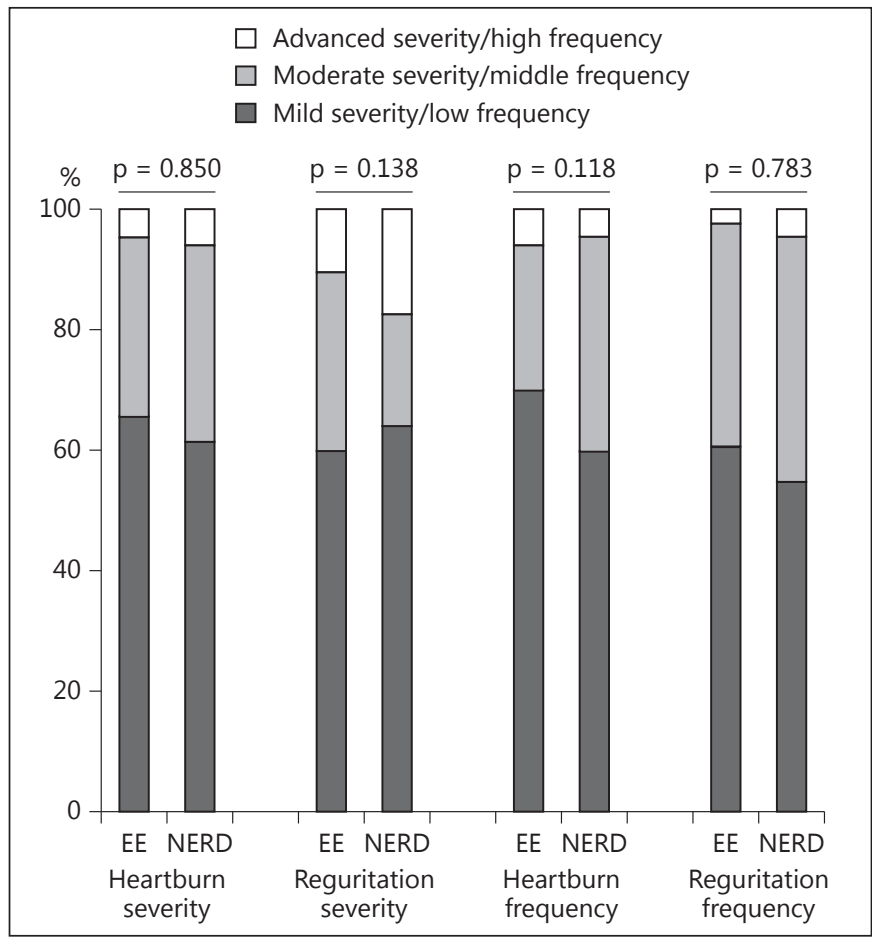

Fig. 1. Specific symptom presentation in patients with GERD.

Two summary scores were also calculated from the responses of the subject: the physical health score and the mental health score. The scores of the SF-36 questionnaire ranged from 0 to 100 on each dimension and on the summary scales, with higher scores indicating better quality of life.

Data are expressed as standard derivation of mean for each of the measured parameters. Gender, hiatal hernia, lifestyle habits and the modified Chinese GERDQ items are expressed as a percentage of the total patient number. A p value $<0.05$ was considered statistically significant. Statistical analyses were done using Pearson's $\chi^{2}$ test or Fisher's exact test to compare the effects of gender on hiatal hernia, lifestyle habits and the modified Chinese GERDQ scores. ANOVA was used to analyze the effects of age, symptom duration, body weight, BMI and scores of the SF-36 questionnaire.

\section{Results}

The patients in the EE group were significantly older (mean $48.94 \pm 17.38$ vs. $43.34 \pm 12.67$ years), predominately male ( 58.6 vs. $39.5 \%$ ), had hiatal hernia (34.5 vs. $17.4 \%)$, greater body weight $(67.57 \pm 15.13$ vs. $61.06 \pm$ $11.08 \mathrm{~kg})$ and BMI $(24.09 \pm 4.61$ vs. $22.68 \pm 3.12)$ than patients in the NERD group. Both the EE and the NERD groups had similar GERD symptoms and lifestyle habits, 


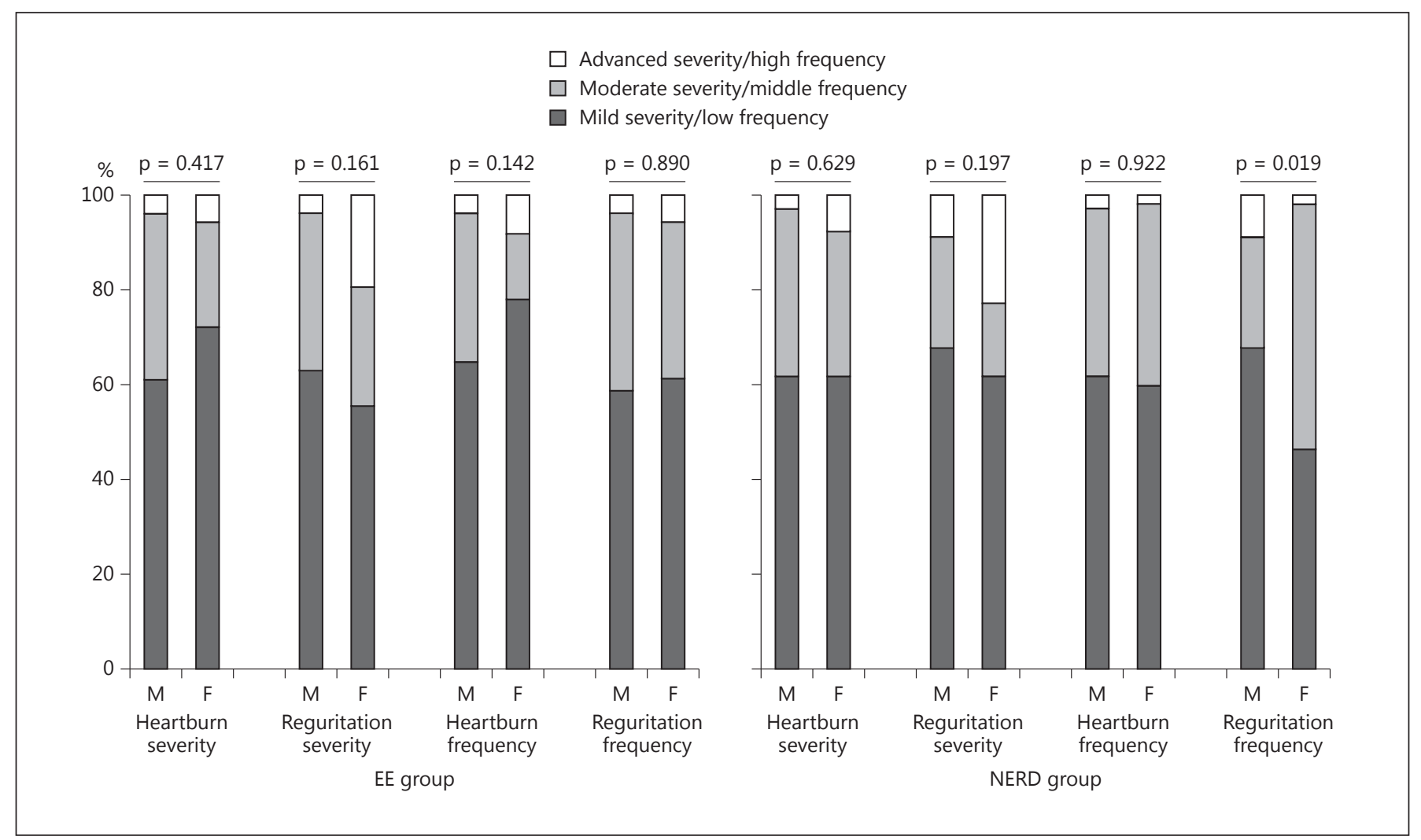

Fig. 2. Specific symptom presentation in male and female patients with GERD.

Table 1. Basic characteristics of the patients with EE and NERD and of the controls

\begin{tabular}{|c|c|c|c|c|c|c|c|c|}
\hline Variable & \multicolumn{2}{|c|}{$\mathrm{EE}(\mathrm{n}=87)$} & \multicolumn{2}{|c|}{ NERD $(\mathrm{n}=86)$} & $\mathrm{p}$ value $^{\mathrm{a}}$ & \multicolumn{2}{|c|}{ Control $(\mathrm{n}=88)$} & $\mathrm{p}$ value \\
\hline Gender & & & & & $0.012^{\mathrm{c}}$ & & & $0.052^{\mathrm{c}}$ \\
\hline Male & $51(58.6)$ & & $34(39.5)$ & & & $42(47.7)$ & & \\
\hline Female & $36(41.4)$ & & $52(60.5)$ & & & $46(52.3)$ & & \\
\hline Hiatal hernia & $30(34.5)$ & & $15(17.4)$ & & $0.011^{\mathrm{c}}$ & & & \\
\hline $\begin{array}{l}\text { Symptom duration, } \\
\text { months }\end{array}$ & & $2.49 \pm 3.44$ & & $2.32 \pm 3.45$ & $0.741^{\mathrm{d}}$ & & & \\
\hline Lifestyle & & & & & & & & \\
\hline Coffee & $50(57.8)$ & & $58(67.4)$ & & $0.135^{\mathrm{c}}$ & $56(63.6)$ & & $0.186^{\mathrm{c}}$ \\
\hline Alcohol & $41(40.2)$ & & $31(30.4)$ & & $0.139^{c}$ & $30(29.4)$ & & $0.164^{\mathrm{c}}$ \\
\hline
\end{tabular}

${ }^{a} \mathrm{p}$ value of the EE group and the NERD group; ${ }^{\mathrm{b}} \mathrm{p}$ value of the EE group, the NERD group and the control group; ${ }^{\mathrm{c}}$ Pearson's $\chi^{2}$ test; ${ }^{\mathrm{d}}$ t test; ${ }^{\mathrm{e}}$ Kruskal-Wallis 1-way ANOVA test. 
including tea, alcohol and coffee consumption and cigarette smoking (table 1).

The rates of severity and frequency of heartburn and acid regurgitation as measured by the modified Chinese GERDQ (fig. 1) were similar between the EE and the NERD groups (heartburn severity score: 1.39 vs. $1.42, \mathrm{p}=$ 0.850 ; regurgitation severity score: 1.51 vs. $1.52, \mathrm{p}=0.138$; heartburn frequency score: 1.36 vs. $1.42, \mathrm{p}=0.118$; regurgitation frequency score: 1.45 vs. $1.50, \mathrm{p}=0.783$ ).

The impact of gender on the symptom presentation is shown in figure 2 . The frequency of regurgitation was significantly greater in the female NERD patients than in the male NERD patients (score: 1.56 vs. $1.41, \mathrm{p}=0.019$ ), but this trend was lost for the symptom of heartburn. There was no difference in the presentations of heartburn or regurgitation between men and women in the EE group.

The total scores, physical health scores and mental health scores as measured by the SF-36 questionnaire are compared. The patients in the NERD group had a lower score (mean total score: $63.93 \pm 16.54$, physical health score: 64.03 \pm 15.94 , mental health score: $58.80 \pm 16.47$ ) than the corresponding values for those in the EE group (mean total score: $66.61 \pm 18.81$, physical health score: $66.13 \pm 18.41$, mental health score: $61.53 \pm 19.98)$. Both the scores in the NERD and the EE groups were lower than those in the control group (mean total score: $72.16 \pm 16.74$, physical health score: $71.02 \pm 16.37$, mental health score: $69.27 \pm 17.36$ ). However, the differences were not statistically significant.

The scores of the SF-36 questionnaire of the two genders were analyzed. The scores of the men and women in the EE group were similar, but significantly lower scores were noted in the female NERD patients (mean total score: $60.67 \pm 17.32$, physical health score: $60.19 \pm 16.31$, mental health score: $55.81 \pm 16.68)$ than in the male NERD patients (mean total score: $68.91 \pm 14.11$, physical health score: $69.91 \pm 13.59$, mental health score: $63.38 \pm$ 15.27). Additionally, compared to the control cases, only the female patients in the NERD group had significantly lower scores in both the physical $(\mathrm{p}=0.002)$ and mental $(\mathrm{p}=0.005)$ dimensions.

\section{Discussion}

Our results proved that there were strong positive correlations of older age, male predominance, lower body weight and BMI, and a higher proportion of hiatal hernia in patients with EE compared to those with NERD, and therefore they were compatible with previous reports [6-10]. However, the lifestyle habits and symptom duration in the two groups were similar, which might be due to the limited number of enrolled cases or the different pathogenesis of EE in the Chinese population.

GERD is very common in the general population, and it has a considerable impact on the daily lives of affected individuals. The two subtypes of GERD (NERD and EE) have different presentations and impacts on the quality of life of the patients. NERD may account for $60 \%$ of all chronic heartburn cases in a community due to the heterogeneous form of the pathophysiological mechanisms and hence should be diagnosed using the $\mathrm{pH}$-metry test [11]. It is now well established that NERD is associated with impaired quality of life, which is at the very least as severe as that related to EE and complicated GERD $[12,13]$.

The severity and frequency of heartburn or regurgitation were similar in the EE and the NERD groups as previously reported [14-17]. However, the female patients in the NERD group had worse symptoms at presentation, especially in the dimension of regurgitation, similar to a previous study [14]. Hence, there could be differential physiopathological mechanisms between heartburn and regurgitation, and the gender had a great impact on the presentation of regurgitation of the NERD cases.

Patients with GERD may present with a broad range of troublesome symptoms that can adversely affect the quality of daily life $[16,18,19]$. In our study, patients with EE and those with NERD had general quality of life scores similar to previous studies $[12,15,16]$. However, compared with the normal population, the NERD patients had a significantly impaired quality of life in both physical and mental health status, but the EE patients did not. This implies that GERD might have a more negative impact on the patients with NERD than on those with EE.

Regarding the impact of gender on quality of life in patients, our study showed that women had significantly lower scores compared to men in the NERD group, but not in the EE group, while a previous study had shown that women had lower general scores [9]. This might be due to a heightened sensitivity and symptom perception of female patients with NERD, or functional heartburn cases might have been misclassified in our study.

The limitations in our study include, first, the fact that the endoscopic findings were recorded by individual endoscopists, and so interobserver conflict and misclassification might have occurred. Second, not all our cases with NERD accepted $\mathrm{pH}$-metry monitoring, and this might have led to 
a misclassification of the individuals with functional heartburn as NERD as previously reported [6]. Third, comorbid diseases of the patients which tend to influence the severity of GERD, such as chronic heart failure or chronic obstructive pulmonary disease, were not considered, and this might have led to inaccurate outcomes. Fourth, the lifestyle characteristics in our study were only limited to the patients' current status. Lastly, our study was hospital-based. Further research using representative samples of the general population is needed to confirm these results.

\section{Conclusion}

The patients with EE were older, predominately male, had more frequently hiatal hernia, higher body weight and BMI than those with NERD. The patients with EE and NERD had similar GERD-specific symptom severity and general quality of life scores. The gender had a great influence on symptom presentation and quality of life of patients with NERD but less impact in those with EE.

\section{References}

1 Vakil N, Veldhuyzen van Zanten S, Kahrilas $\mathrm{P}$, et al: The Montreal definition and classification of gastro-esophageal reflux disease (GERD) - a global evidence-based consensus. Am J Gastroenterol 2006;101:1900-1920.

-2 Ronkainen J, Aro P, Storskrubb T, et al: Gastroesophageal reflux symptoms and health related quality of life in the adult general population - the Kalixandra study. Aliment Pharmacol Ther 2006;23:1725-1733.

$>3$ Armstrong D, Bennett JR, Blum A, et al: The endoscopic assessment of esophagitis: a progress report on observer agreement. Gastroenterology 1996;111:85-92.

$\checkmark 4$ Wiklund I: Review of the quality of life and burden of illness in gastroesophageal reflux disease. Dig Dis 2004;22:108-114.

$>5$ Wahlqvist P, Karlsson M, Johnson D, et al: Relationship between symptom load of gastro-oesophageal reflux disease and health-related quality of life, work productivity, resource utilization and concomitant diseases: survey of a US cohort. Aliment Pharmacol Ther 2008;27:960-970.

-6 Oh JH, Kim TS, Choi MG, et al: Relationship between psychological factors and quality of life in subtypes of gastroesophageal reflux disease. Gut Liver 2009;3:259-265.
7 Labenz J, Jaspersen D, Kulig M, et al: Risk factors for erosive esophagitis: a multivariate analysis based on the ProGERD study initiative. Am J Gastroenterol 2004;99:1652-1656.

$>8$ Lee SW, Lien HC, Chang CS, et al: Impact of body mass index and gender on quality of life in patients with gastroesophageal reflux disease. World J Gastroenterol 2012;18:50905095.

-9 Ronkainen J, Aro P, Storskrubb T, et al: High prevalence of gastroesophageal reflux symptoms and esophagitis with or without symptoms in the general adult Swedish population: a Kalixanda study report. Scand J Gastroenterol 2005;40:275-285.

10 Du J, Liu J, Zhang H, et al: Risk factors for gastroesophageal reflux disease, reflux esophagitis and non-erosive reflux disease among Chinese patients undergoing upper gastrointestinal endoscopic examination. World J Gastroenterol 2007;13:6009-6015.

11 Savarino E, Zentilin P, Savarino V: NERD: an umbrella term including heterogenous subpopulations. Nat Rev Gastroenterol Hepatol 2013;10:371-380.

12 Fass R, Fennerty MB, Vakil N: Non-erosive reflux disease (NERD) - current concepts and dilemmas. Am J Gastroenterol 2001;96:303-314.

13 Quigley EM: Non-erosive reflux disease: part of the spectrum of gastrooesophageal reflux disease, a component of functional dyspepsia, or both? Eur J Gastroenterol Hepatol 2001; 13(suppl 1):S13-S18.
14 Lippmann QK, Crockett SD, Dellon ES, et al: Quality of life in GERD and Barrett's esophagus is related to gender and manifestation of disease. Am J Gastroenterol 2009; 104:26952703.

15 Kovacs Z, Kerekgyarto O: Psychological factors, quality of life, and gastrointestinal symptoms in patients with erosive and non-erosive reflux disorder. Int J Psychiatry Med 2007;37: 139-150.

$>16$ Kulig M, Leodolter A, Vieth M, et al: Quality of life in relation to symptoms in patients with gastro-oesophageal reflux disease - an analysis based on the ProGERD initiative. Aliment Pharmacol Ther 2003; 18:767-776.

17 Fennerty MB, Johnson DA: Heartburn severity does not predict disease severity in patients with erosive esophagitis. Med Gen Med 2006; 8:6.

18 Chen M, Xiong L, Chen H, et al: Prevalence, risk factors and impact of gastroesophageal reflux disease symptoms: a population-based study in South China. Scand J Gastroenterol 2005;40:759-767.

19 Revicki DA, Wood M, Maton PN, et al: The impact of gastroesophageal reflux disease on health-related quality of life. Am J Med 1998; 104:252-258. 